\section{Formation and Stability of Tricyano Ion}

\author{
M. T. BECK, V. GÁSPÁR and D. P. GOEL* \\ Institute of Physical Chemistry, Kossuth Lajus University, \\ H-4010 Debrecen, Hungary
}

Received December 22, 1978

As is well known, halogens form with halide ions trihalide ions of different stability. However, only very limited information can be found on the similar interaction between the different pseudohalogen molecules and pseudohalide ions. Our interest in this problem was initiated by a study of reactions between cyanogen and different cyanocomplexes.

In the reaction of hydrogen cyanide with cyanogen different heterocyclic compounds and diiminosuccinic acid dinitrile are formed in non-aqueous solution $[1,2]$. It is assumed that an intermediate of the composition $(\mathrm{CN})_{3}^{-}$plays a role in the mechanism of the reaction [3] but it cannot be regarded as an analogue of trihalogenide ions. We performed experiments to gain information on the nature of the reversible interaction between cyanide ion and cyanogen. The main difficulty in this study is caused by the fairly rapid hydrolysis of cyanogen. The rate of hydrolysis increases with increasing $\mathrm{pH}$ and this places a limitation to the application of a cyanide selective electrode. To detect the reversible interaction and to determine the stability constant spectrophotometric measurements were made using a fast mixing technique. Taking into account that the hydrolysis of cyanogen is much slower in not anhydrous organic solvents, liquid-liquid distribution experiments were also performed.

\section{Experimental}

Cyanogen was prepared by the procedure suggested by Hahn [4]. It was dissolved in cyclohexane for the extraction experiments and in ethanol for the spectrophotometric ones. These solutions were prepared just before the experiments and the cyanogen content was determined by cyanide selective electrode after alkaline hydrolysis.

In the extraction experiments $3.0 \mathrm{M}$ sodium cyanide, in the spectrophotometric experiments $1.0 \mathrm{M}$ sodium cyanide stock solutions were used. These solutions were kept in plastic vessels in the dark. These solutions were frequently prepared and used only if no yellowish discolouration occurred. The ionic strength was adjusted with sodium perchlorate.

*D. P. Goel, St. Stephen's College, Delhi-110007, India.
In cyclohexane solution cyanogen has a characteristic absorption band at $222 \mathrm{~nm}$, where the molar absorbance is 13. Cyanogen concentration was calculated from the measured absorbance at this wavelength. The distribution coefficient of cyanogen was calculated from the measured absorbance of the cyclohexane phase before and after the extraction with 3.0 $M$ sodium perchlorate solution, while the apparent distribution coefficient was calculated from the absorbance of the cyclohexane phase before and after extraction with cyanide solutions $\left(\mathrm{c}_{\mathrm{NaCN}}+\mathrm{c}_{\mathrm{NaClO}_{4}}=3\right)$. The volume of the organic and the aqueous phase was the same; the concentration of cyanide in the aqueous phase ranged from 0.1 to $2.0 \mathrm{M}$, while the concentration of cyanogen before extraction varied between 1 and $5 \times 10^{-2} \mathrm{M}$.

For the spectrophotometric measurements a Hitachi-Perkin Elmer 139 single beam instrument was used using a home-made fast mixing apparatus. The mixing time was less than $3 \mathrm{sec}$. The interaction was followed by measuring the absorbance at $275 \mathrm{~nm}$ (slit width $0.5 \mathrm{~nm}$ ) where the product of the fast reaction has a characteristic absorbance. For the evaluation of the results the absorbance was measured as a function of time and the absorbance values extrapolated to zero time $\left(A_{0}\right)$ were used. The first syringe was filled with an ethanolic solution of cyanogen, while the second syringe contained the aqueous sodium cyanidesodium perchlorate solution. The concentration of cyanogen in ethanol varied between 0.01 and $0.07 \mathrm{M}$, the concentration of cyanide in the aqueous solution ranged from 0.05 to $0.5 M$, the ionic strength was adjusted with sodium perchlorate to $1 M$. The solutions were thermostated to $25^{\circ} \mathrm{C}$.

\section{Results and Discussion}

When the cyclohexane solution of cyanogen is extracted by aqueous cyanide solution the originally colorless aqueous phase becomes yellowish and after longer time (several days) a brown precipitate is formed. In the spectrum of the yellow solution there is a new shoulder at $350 \mathrm{~nm}$ and a new band at 288 $\mathrm{nm}$. Similar spectral changes occur when an ethanolic cyanogen solution is mixed with aqueous cyanide solution. In this case there is a new peak at $275 \mathrm{~nm}$ and a shoulder at $310-320 \mathrm{~nm}$ with intensity increasing in time.

These experiments indicate that a fast and a slow reaction can be distinguished. It is assumed that the fast reaction is the formation of the weak tricyanide ion, while in the slow stage different and not welldefined organic compounds are formed.

As appears from the data in Table I the absorbance extrapolated to $t=0$ is proportional to the 
TABLE I. Calculation of Products $\mathrm{K} \epsilon$ from Spectrophoto-

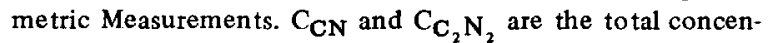
trations of cyanide and cyanogen, resp., $\epsilon$ is the molar absorbance of tricyanide ion, $K$ is the stability constant, $d(=0.76$ $\mathrm{cm}$ ) is the thickness of the cuvette and $A_{0}$ is the absorbance extrapolated to $t=0$.

\begin{tabular}{llll}
\hline $\begin{array}{l}\mathrm{C}_{\mathrm{CN}} \\
\mathrm{mol} \mathrm{dm}\end{array}$ & $\begin{array}{l}\mathrm{C}_{\mathrm{C}_{2} \mathrm{~N}_{2}} \\
\mathrm{~mol} \mathrm{dm}^{-3}\end{array}$ & $\begin{array}{l}\mathrm{A}_{0} / \mathrm{d} \\
\mathrm{cm}^{-1}\end{array}$ & $\begin{array}{l}\mathrm{K} \epsilon \\
\mathrm{mol}^{-2} \mathrm{dm}^{6} \mathrm{~cm}^{-1}\end{array}$ \\
\hline 0.025 & 0.0346 & 0.064 & 74.0 \\
0.035 & 0.0346 & 0.097 & 80.1 \\
0.045 & 0.0692 & 0.298 & 95.7 \\
0.050 & 0.0692 & 0.328 & 94.8 \\
0.100 & 0.0105 & 0.063 & 60.0 \\
0.125 & 0.0105 & 0.099 & 75.7 \\
0.150 & 0.0158 & 0.227 & 95.6 \\
0.200 & 0.0105 & 0.120 & 57.3 \\
0.300 & 0.0158 & 0.351 & 74.1 \\
0.400 & 0.0158 & 0.491 & 77.7 \\
& $\overline{\mathrm{K} \epsilon}=78.5 \pm 13.0 \mathrm{~mol}^{-2} \mathrm{dm}^{6} \mathrm{~cm}^{-1}$ \\
\hline
\end{tabular}

total concentration of both cyanogen and cyanide. Such a behaviour can be expected if the value of the equilibrium constant of the reaction

$$
\mathrm{CN}^{-}+(\mathrm{CN})_{2}=(\mathrm{CN})_{3}^{-}
$$

is small. The change of the absorbance in this case is entirely due to the absorbance of the product and is given by the following equation

$$
\mathrm{A}_{0}=\epsilon \cdot \mathrm{K} \cdot \mathrm{C}_{\mathrm{CN}} \mathrm{C}_{\mathrm{C}_{2} \mathrm{~N}_{2}} \mathrm{~d}
$$

where $\mathrm{C}_{\mathrm{CN}}$ and $\mathrm{C}_{\mathrm{C}_{2} \mathrm{~N}_{2}}$ are the total concentrations of cyanide and cyanogen, resp., $\epsilon$ is the molar absorbance of $(\mathrm{CN})_{3}^{-}, \mathrm{K}$ is the stability constant. In the case of formation of rather weak complexes only the $\mathrm{K} \epsilon$ product can be obtained from spectrophotometric measurements. Its value is given in the last column of Table I.

However, the liquid-liquid distribution experiments provided the numerical value for the stability constant. Comparing the partition coefficient of cyanogen

$$
\mathrm{P}=\frac{\left[\mathrm{C}_{2} \mathrm{~N}_{2}\right]_{0}}{\left[\mathrm{C}_{2} \mathrm{~N}_{2}\right]_{\mathrm{v}}}
$$

the distribution ratio of cyanogen

$$
\mathrm{D}=\frac{\left[\mathrm{C}_{2} \mathrm{~N}_{2}\right]_{0}}{\left[\mathrm{C}_{2} \mathrm{~N}_{2}\right]_{\mathrm{V}}+\left[(\mathrm{CN})_{3}^{-}\right]}
$$

and a simple equation can be obtained for the calculation of the stability constant

$$
\mathrm{K}=\frac{\mathrm{P} / \mathrm{D}-1}{\left[\mathrm{CN}^{-}\right]}
$$

TABLE II. Calculation of Stability Constant from the Liquid - Liquid Distribution Experiments. $\mathbf{A}_{1}=$ absorbance of cyclohexane solution of cyanogen before extraction; $A_{2}=$ absorbance of cyclohexane solution of cyanogen after extraction with $3.0 \mathrm{M}$ sodium perchlorate solution; $\mathrm{A}_{3}=$ absorbance of cyclohexane solution of cyanogen after extraction with cyanide solution $\left(\mathrm{c}_{\mathrm{NaCN}}+\mathrm{c}_{\mathrm{NaClO}_{4}}=3.0\right)$.

\begin{tabular}{|c|c|c|c|c|c|c|c|}
\hline$A_{1}$ & $A_{2}$ & $\mathbf{P}$ & $\begin{array}{l}{\left[\mathrm{CN}^{-}\right]} \\
\times 10^{2} \\
\mathrm{~mol} \\
\mathrm{dm}^{-3}\end{array}$ & $\mathbf{A}_{3}$ & $\mathrm{D}$ & $\mathbf{P} / \mathbf{D}$ & $\begin{array}{l}\mathrm{K} \\
\mathrm{mol}^{-1} \\
\mathrm{dm}^{3}\end{array}$ \\
\hline 0.380 & 0.092 & 0.32 & 8.8 & 0.090 & 0.310 & 1.03 & 0.34 \\
\hline 0.380 & 0.092 & 0.32 & 28.2 & 0.086 & 0.293 & 1.09 & 0.33 \\
\hline 0.380 & 0.092 & 0.32 & 48.2 & 0.082 & 0.275 & 1.16 & 0.33 \\
\hline 0.335 & 0.081 & 0.32 & 72.9 & 0.070 & 0.264 & 1.21 & 0.29 \\
\hline 0.540 & 0.115 & 0.27 & 95.8 & 0.092 & 0.205 & 1.32 & 0.33 \\
\hline 0.335 & 0.081 & 0.32 & 122.0 & 0.063 & 0.232 & 1.38 & 0.31 \\
\hline \multirow[t]{2}{*}{0.540} & 0.115 & 0.27 & 195.7 & 0.080 & 0.174 & 1.55 & 0.28 \\
\hline & \multicolumn{3}{|c|}{$P=0.30 \pm 03$} & \multicolumn{4}{|c|}{$\mathrm{K}=0.31 \pm 0.03$} \\
\hline
\end{tabular}
The volume of the organic and aqueous phase was the same, thus $\mathbf{P}=\mathbf{A}_{2} / \mathbf{A}_{1}-\mathbf{A}_{2}=$ partition coefficient of cyanogen; $D=A_{3} / A_{1}-A_{3}=$ apparent partition coefficient of cyanogen.

The results of the extraction experiments are summarized in Table II. As can be seen from the data of the last column, the value of the stability constant of tricyanide ion is $\mathrm{K}=0.31 \pm 0.03 \mathrm{~mol}^{-1} \mathrm{dm}^{3}$. This is in good agreement with the results of the spectrophotometric experiments indicating the formation of a rather unstable ion.

We believe that the results of the two independent approaches strongly indicate that there is a reversible reaction between the cyanide and cyanogen leading to the formation of the unstable tricyanide ion. If the measured spectral changes and the change of the distribution ratio of cyanogen between the organic and the aqueous phase were assigned to some irreversible reactions the equilibrium constant obtained would be higher by many orders of magnitude.

\section{References}

1 R. W. Begland, A. Cairncross, D. S. Donald, D. R. Hartter, W. A. Sheppard and O. W. Webster, J. Am. Chem. Soc., 93, 4953 (1971).

2 D. W. Wiley, O. W. Webster and E. P. Blanchard, J. Org. Chem., 41, 1889 (1976).

3 T. Austad and S. Esperas, Acta Chem. Scand., A 28, 892 (1974).

4 C. Hahn, Ber., 68, 1974 (1935). 